㱐 


\title{
Lehren und Lernen
}

\author{
Herausgegeben von \\ Universitätsprofessor Dr. Dr. h.c. Frank Achtenhagen
}

Bisher erschienene Werke:

Preiß, Didaktik des wirtschaftsinstrumentellen Rechnungswesens 


\title{
Didaktik des
}

\section{wirtschaftsinstrumentellen}

Rechnungswesens

\author{
Von \\ Dr. Peter Preiß
}

Seminar für Wirtschaftspädagogik

Georg-August-Universität Göttingen

R.Oldenbourg Verlag München Wien 


\section{Die Deutsche Bibliothek - CIP-Einheitsaufnahme}

\section{Preiß, Peter:}

Didaktik des wirtschaftsinstrumentellen Rechnungswesens / Peter

Preiß. - München ; Wien : Oldenbourg, 1999

(Lehren und Lernen)

ISBN 3-486-25240-2

\section{(C) 1999 Oldenbourg Wissenschaftsverlag GmbH}

Rosenheimer Straße 145, D-81671 Munchen

Telefon: (089) 45051-0, Internet: http://www.oldenbourg.de

Das Werk einschließlich aller Abbildungen ist urheberrechtlich geschützt. Jede Verwertung außerhalb der Grenzen des Urheberrechtsgesetzes ist ohne Zustimmung des Verlages unzulässig und strafbar. Das gilt insbesondere für Vervielfaltigungen, Übersetzungen, Mikroverfilmungen und die Einspeicherung und Bearbeitung in elektronischen Systemen.

Gedruckt auf săure- und chlorfreiem Papier

Gesamtherstellung: WB-Druck, Rieden 
Was ein Dach wert ist, wissen wir nicht mehr, wenn wir wissen, was es kostet.

Gert Heidenreich: Die Nacht der Händler. 
